FRANÇA, F.H.; VILLAS BÔAS, G.L.; CASTELO BRANCO, M. Ocorrência de Bemisia argentifolii Bellows \& Perring (Homoptera: Aleyrodidae) no Distrito Federal. Anais da Sociedade Entomológica do Brasil, Londrina, v. 25, $\mathrm{n}$. 2, p. 369-372, 1996.

GERLING, D.; MAYER, R.T., ed. Bemisia: 1995 taxonomy, biology, damage, control and management. Andover: Intercept, 1996. 702 p. GRAVENA, S.; CHURATA-MASCA, M.G.C.; ARAI, J.; RAGA, A. Manejo integrado da mosca branca Bemisia tabaci (Gennadius, 1889) em cultivares de tomateiro de crescimento determinado visando redução de virose do mosaico dourado. Anais da Sociedade Entomológica do Brasil, Porto Alegre, v. 13, n. 1, p. 35-45, 1984.

LOURENÇÃO, A.L.; NAGAI, H. Surtos populacionais de Bemisia tabaci no Estado de São Paulo. Bragantia, Campinas, v. 53, n. 1, p. 53-59, 1994.

MELO, P.C.T. Mosca branca ameaça produção de hortaliças. Campinas: ASGROW, [1992?]. 2 p. (ASGROW. Semente. Informe Técnico).
MIZUNO, A.C.R.; VILLAS BÔAS, G.L. Biologia da mosca-branca (Bemisia argentifolii) em tomate e repolho. Brasília: EMBRAPA-CNPH, 1997. 5 p. (EMBRAPA-CNPH. Pesquisa em Andamento da Embrapa Hortaliças, 1).

PERRING, T.M.; COOPER, A.D.; RODRIGUEZ, R.J.; FARRAR, C.A.; BELLOWS JUNIOR, T.S. Identification of a whitefly species by genomic and behavioral studies. Science, v. 259, p. 74-77, 1993.

PRICE, P.W. Insect ecology. 2.ed. New York: J. Wiley, 1984. 607 p.

SALAS, J.; MENDOZA, O. Biology of the sweetpotato whitefly (Homoptera: Aleyrodidae) on tomato. Florida Entomologist, v. 78, n. 1, p. 154-160, 1995.

SALGUERO, V. Perspectivas para el manejo del complejo mosca blanca-virosis. In: HILJE, L.; ARBOLEDA, O. Las moscas blancas (Homoptera: Aleyrodidae) en America Central e El Caribe. Turrialba: CATIE, 1992. p. 20-26. (CATIE. Serie Técnica. Informe Técnico, 205), 1993.
SILVEIRA NETO, S.; NAKANO, O.; BARBIN, D.; VILLA NOVA, N.A. Manual de ecologia dos insetos. São Paulo, Agronômica Ceres, 1976. 419 p.

TSAI, J.H.; WANG, K. Development and reproduction of Bemisia argentifolii (Homoptera: Aleyrodidae) on five host plants. Environmental Entomology, v. 25, n. 4, p. 810-816, 1996.

VILLAS BÔAS, G.L.; FRANÇA, F.H.; ÁVILA, A.C.; BEZERRA, I.C. Manejo integrado da mosca-branca Bemisia argentifolii. Brasília: EMBRAPA-CNPH, 1997. 11 p. (EMBRAPACNPH. Circular técnica da EMBRAPA Hortaliças, 9).

YEE, W.L.; TOSCANO, N.C. Ovipositional preference and development of Bemisia argentifolii (Homoptera: Aleyrodidae) in relation to alfafa. Journal of Economic Entomology, v. 89, n. 4, p. 870-876, 1996.

FRANÇA, F.H.; RITSCHEL, P.S. Avaliação de acessos de batata-doce para resistência à broca-da-raiz, crisomelídeos e elaterídeos. Horticultura Brasileira, Brasília, v. 20, n. 1, p. 79-85, março 2.002.

\title{
Avaliação de acessos de batata-doce para resistência à broca-da-raiz, crisomelídeos e elaterídeos.
}

\author{
Félix Humberto França; Patrícia Silva Ritschel \\ Embrapa Hortaliças, C. Postal 218, 70.359-970 Brasília-DF. E-mail: franca@cnph.embrapa.br
}

\section{RESUMO}

Foram avaliados para resistência a danos causados por insetos nas folhas e raízes, no campo, 366 acessos do Banco Ativo de Germoplasma de batata-doce da Embrapa Hortaliças. Os insetos de interesse foram Diabrotica spp., Conoderus sp., Epitrix sp., e a broca-da-raiz da batatadoce, Euscepes postfasciatus. Considerando o estrato raízes, aproximadamente $21 \%$ dos acessos avaliados mostraram-se resistentes a crisomelídeos e elaterídeos, tendo sido identificados pelo menos sete clones melhores que a referência padrão de resistência àqueles insetos, a cultivar Brazlândia Roxa. Sete acessos, entre esses o CNPH 005, CNPH 026 e CNPH 258 mostraram-se bastante homogêneos e consistentes em três avaliações. Esses mesmos clones, além dos clones CNPH 088, CNPH 295, CNPH 314 e CNPH 318 mostraram-se entre os mais resistentes à broca-da-raiz, porque tiveram $7 \%$ ou menos das suas raízes tuberosas danificadas por Euscepes postfasciatus enquanto as cultivares Brazlândia Branca e Princesa obtiveram, respectivamente, 23,3\% e $53,3 \%$ de danos. Outros nove acessos foram classificados como mais suscetíveis que essas cultivares. A aplicação desses resultados no manejo integrado de pragas em batata-doce é discutido.

Palavras-chave: Ipomoea batatas, Chrysomelidae, Elateridae, Diabrotica spp., Conoderus sp., Epitrix sp., Euscepes postfasciatus, resistência de plantas a insetos, insetos de solo, manejo integrado de pragas.

\begin{abstract}
Screening of sweet potato accessions for resistance to the West Indian sweet potato weevil, chrysomelids and elaterids.

Three hundred sixty six sweet potato plant accessions of the Sweet potato Germplasm Bank of Embrapa Hortaliças (Brazil) were evaluated in the field for resistance to the Wireworm-Diabrotica-Systena (WDS) pest complex: Diabrotica spp., Conoderus sp., Epitrix sp., and West Indian sweet potato weevil, Euscepes postfaciatus. About $21 \%$ of all plant accessions showed high resistance to chrysomelids and elaterids. Seven clones, among them CNPH 005, CNPH 026 and CNPH 258 were more resistant than the standard resistant commercial cultivar Brazlândia Roxa. These sweet potato accessions and CNPH 088, CNPH 295, CNPH 314 and CNPH 318, were the most promising sources of resistance against the West Indian sweet potato weevil because they had $7 \%$ or less, of their roots damaged by Euscepes postfasciatus, compared to commercial cultivars Brazlândia Branca $(23.3 \%)$ and Princesa $(53.3 \%)$. The application of these results in an integrated control of sweet potato pests approach is discussed.
\end{abstract}

Keywords: Ipomoea batatas, Chrysomelidae, Elateridae, Diabrotica spp, Conoderus sp, Epitrix sp, Euscepes postfasciatus, sweet potato, West Indian sweet potato weevil, host plant resistance, soil insects, integrated pest management.

(Aceito para publicação em 07 de dezembro de 2.001).

A diversidade de espécies de insetos associados à batata-doce e parentes silvestres próximos nas Améri- cas é atribuída por Raman \& Alleyne (1991), ao fato de que o centro de origem de várias espécies do gênero
Ipomoea é localizado nas Américas do Sul e Central. São exemplos de insetos chave da cultura os adultos e as larvas 
de várias espécies de crisomelídeos, elaterídeos e da broca-da-raiz $E$. postfasciatus. Essa é a principal praga da cultura em vários países das Américas do Sul e Central, Caribe e Pacífico Sul. Enquanto extensa pesquisa realizada resultou em táticas úteis de manejo integrado visando o controle de crisomelídeos, poucos trabalhos foram realizados procurando apresentar soluções para os danos e as perdas causadas pela broca-da-raiz.

$\mathrm{O}$ controle químico das pragas da batata-doce em anos recentes no Brasil tem se mostrado inviável pelo alto custo dos agrotóxicos e inexistência de produtos registrados para a cultura. Algumas práticas agronômicas têm provado serem eficientes ao longo dos últimos 50 anos no controle de pragas da cultura como a utilização de ramas sadias; boa preparação do solo evitando-se o torroamento excessivo; irrigação adequada visando manter o solo úmido, evitando-se assim a formação de rachaduras que facilitem a entrada de insetos para oviposição e alimentação; rotação de culturas e amontoa alta (Bondar, 1930; Bondar, 1931). A essas medidas associou-se a utilização de variedades resistentes como importante componente do manejo integrado de pragas da batata-doce (Miranda et al.,1984).

Cultivares de batata-doce resistentes a insetos de solo das famílias Chrysomelidae e Elateridae foram lançadas em 1975 nos EUA (Jones et al.,1975), e desde então, a metodologia de seleção de germoplasma tem sido aperfeiçoada (Rolston et al., 1979; Mullen et al., 1980; Barlow \& Rolston, 1981; Jones et al., 1981) resultando na liberação de novas cultivares (Mullen et al., 1980; Jones et al., 1983). A resistência da batata-doce a insetos de solo como a larva-alfinete (Diabrotica spp.), larva-arame (Conoderus spp.) e pulgado-fumo (Epitrix spp.) é presumida estar localizada na pele das raízes, mas o fator que a determina ainda não foi identificado (Cuthbert \& Davis, 1971). O desconhecimento deste fato, porém, não impediu o desenvolvimento de cultivares resistentes (Jones et al., 1981).

Um acervo extremamente consistente de informações sobre a biologia, interações tróficas e resistência genéti- ca a Megastes spp. e Euscepes postfaciatus (Fairmaire) foi produzido através das teses orientadas pelo Prof. Dr. Antonio F. de Souza Leão Veiga, na Universidade Federal Rural de Pernambuco, sendo que alguns destes trabalhos discriminaram claramente os níveis de resistência encontrados (Martinez, 1985; Novo, 1983; Garcia, 1989; Braga, 1993). Publicações sobre a resistência de batata-doce à broca-daraiz são relativamente recentes na literatura internacional e parte destas refere-se a avaliações realizadas em campo ou a trabalhos conduzidos em laboratório. Sabe-se que os poucos materiais selecionados tiveram baixa qualidade agronômica (Raman \& Alleyne, 1991).

A partir de 1979 na Embrapa Hortaliças, foi realizado um trabalho de desenvolvimento metodológico (França et al., 1983a), avaliação (França et al., 1983b) e seleção de germoplasma de batata-doce para resistência a crisomelídeos (Miranda \& França, 1988; França, 1989; Silveira \& Maluf, 1994) que culminou com a liberação em 1984 da cultivar resistente Brazlândia Roxa. Variabilidade genética em batata-doce para resistência a ácaros foi demonstrada por Maluf et al. (1987). Mais recentemente, significativo sucesso foi obtido na busca por germoplasma resistente a crisomelídeos resultando no lançamento das cultivares 'Palmas' e 'Caruanã', no Estado de Tocantins, mais resistentes àqueles insetos que o padrão conhecido até então (M. A. da Silveira, informação pessoal).

Este trabalho tem por objetivo apresentar os resultados da caracterização do Banco Ativo de Germoplasma (BAG) de batata-doce da Embrapa-Hortaliças (Ritschel et al., 1999) para resistência a artrópodes de folhas, ramas e raízes, com ênfase à broca-da-raiz da batatadoce, E. postfaciatus, crisomelídeos e elaterídeos e a importância destes resultados no manejo de pragas da cultura.

\section{MATERIAL E MÉTODOS}

\section{Avaliação preliminar}

Trezentos e sessenta e seis acessos do BAG de batata-doce da Embrapa Hortaliças foram plantados em dezembro de 1995 e avaliados em fins de maio de
1996, correspondendo aproximadamente ao ciclo vegetativo de 180 dias. Uma amostra de oitenta acessos plantada em experimento independente do anterior, mas em área adjacente a ele, foi avaliada em setembro de 1996, correspondendo aproximadamente a um ciclo vegetativo de 270 dias, visando verificar se a manutenção de raízes no solo por mais tempo implicaria no aumento ou não dos danos causados por insetos.

As ramas utilizadas nos experimentos foram obtidas a partir de viveiro constituído para este fim. Estas contavam com aproximadamente 60 dias de idade, e mediam entre 30 e $40 \mathrm{~cm}$ de comprimento, contendo de 6 a 10 entrenós. Metade destes foram enterrados no solo, preparados em camalhões de $25 \mathrm{~cm}$ de altura. $\mathrm{O}$ espaçamento utilizado foi $0,80 \mathrm{~m}$ entre linhas e $0,30 \mathrm{~m}$ entre covas. O solo foi arado uma vez e gradeado utilizando-se grade niveladora para bom destorroamento da área. Foram realizadas duas amontoas ou recuperação dos camalhões até 60 dias após o plantio das ramas.

No plantio foram aplicados, por hectare, $30 \mathrm{Kg} \mathrm{N}, 150 \mathrm{Kg}$ de $\mathrm{P}_{2} \mathrm{O}_{5}$ e $150 \mathrm{Kg}$ de K2O. Trinta dias após o plantio foram aplicados $30 \mathrm{Kg}$ de $\mathrm{N}$ em cobertura. Os demais tratos culturais foram aqueles recomendados para a cultura (Miranda et al., 1984). Foram utilizadas até 10 plantas/cova por acesso para avaliação quantitativa dos danos nas raízes. Não foram usados agrotóxicos no solo ou em pulverização na área dos experimentos. Os genótipos foram submetidos à ação de populações naturais dos insetos de interesse.

Os acessos foram avaliados para danos causados por crisomelídeos dos gêneros Diabrotica spp., Epitrix sp., e elaterídeos do gênero Conoderus sp., nas folhas e nas raízes, através da determinação do número de furos em amostras de folhas coletadas em cinco plantas ( 1 folha/planta $=5$ folhas $)$ e de quinze raízes tuberosas por acesso. Atribuiuse ainda nota de dano considerando-se o aspecto geral das folhas de todas as plantas ou das raízes tuberosas colhidas de cada parcela. Foi utilizada uma escala de notas, onde a nota um correspondia a folhas ou raízes pouco danificadas; parcelas com folhas e raízes 
Tabela 1. Distribuição de frequência das notas de dano em folhas de 366 acessos de batatadoce e número médio de furos nas folhas. Brasília, Embrapa Hortaliças, 1996.

\begin{tabular}{ccc}
\hline \multicolumn{2}{c}{ Avaliação preliminar I } & Média \pm EPM ${ }^{1}$ \\
\hline Notas de dano $^{2}$ & Frequência & (n $^{\mathbf{0}}$ de furos) \\
\hline 1 & 36 & $2,8 \pm 0,5$ \\
2 & 170 & $8,3 \pm 0,6$ \\
3 & 146 & $13,7 \pm 1,1$ \\
4 & 14 & $22,7 \pm 6,1$ \\
& 366 & \\
\hline
\end{tabular}

Média geral de furos/folha

$10,5 \pm 0,3$

${ }^{1}$ Erro padrão da média

${ }^{2}$ Notas de dano: 1 = folha pouco danificada; .......; 5 = folha muito danificada

muito danificadas receberam nota cinco (França et al., 1983a). A cultivar Brazlândia Roxa foi considerada padrão resistente a crisomelídeos, e as cultivares Brazlândia Branca, Brazlândia Rosada e Coquinho os padrões suscetíveis.

As raízes tuberosas de batata-doce foram avaliadas para danos da broca-daraiz, tendo sido determinada a porcentagem de raízes sadias e danificadas em cada acesso. Foi obtida a estatística descritiva dos dados (média, desvio padrão, erro padrão da média, amplitude, etc), de modo a permitir que os genótipos fossem agrupados nas classes de dano: altamente suscetíveis $(81-100 \%$ de dano), suscetíveis (61-80\%), moderadamente resistentes (41-60\%), resistentes (21-40\%) e altamente resistentes (0$20 \%$ ). Não se conhecendo entre os acessos de batata-doce disponíveis no BAG algum resistente à broca-da-raiz, estabeleceu-se antes da avaliação dos genótipos, que a resistência seria caracterizada pela presença de danos em até $40 \%$ das raízes tuberosas de cada acesso. A suscetibilidade seria atribuída aos acessos com mais de $61 \%$ de raízes tuberosas danificadas. Essas, após colhidas, foram deixadas secar ao relento durante à noite, no próprio local da colheita, antes de serem armazenadas.

Ensaio para confirmação de resistência e suscetibilidade em raízes tuberosas

Considerando-se as avaliações dos dois experimentos anteriores, o total de 28 acessos classificados como resistentes e suscetíveis, além das cultivares lançadas pela Embrapa Hortaliças, Brazlândia Branca, Rosada, Roxa e Princesa, foram avaliados para resistên- cia a crisomelídeos e broca-da-raiz (Tabela 4). Um ensaio, onde foram utilizadas 10 plantas/cova por acesso para avaliação quantitativa dos danos nas raízes, delineado em blocos casualizados com três repetições, foi conduzido no período de janeiro a junho de 1997, na mesma área em que foi plantada a avaliação preliminar, visando garantir a presença de insetos causadores de danos. A obtenção de ramas e demais procedimentos acerca da instalação (espaçamento, adubação), condução e avaliação do ensaio foram realizados como descrito anteriormente. Procedeuse à análise de variância, sendo as médias separadas pelo teste estatístico da Diferença Mínima Significativa.

\section{RESULTADOS E DISCUSSÃO}

\section{Avaliação preliminar}

Há variabilidade genética em batata-doce para danos causados por insetos nas folhas (Tabela 1), ainda que nesta avaliação tenhamos verificado que aproximadamente $95 \%$ dos genótipos do BAG de batata-doce da Embrapa Hortaliças são tolerantes a danos causados por insetos nas folhas. Os danos foliares foram na sua maioria causados por coleópteros das famílias Chrysomelidae (Diabrotica spp., e Epitrix sp.), Elateridae e em menor instância por Curculionidae. Observou-se também, consideráveis populações de afídeos e cigarrinhas, estas últimas, provavelmente do gênero Empoasca spp., às quais podem ser atribuídos os sintomas de viroses observados na maioria dos acessos.

Mesmo que inseticidas não tenham sido pulverizados, o número médio de furos por folha, $10,5+0,3$, pode ser considerado baixo (Tabela 1). Como resistentes foram consideradas as parcelas que obtiveram nota média equivalente a dois e nenhum acesso obteve nota cinco (Tabela 1). Provavelmente a alimentação de coleópteros, que causa grande impacto visual ao agricultor devido às lesões grandes ou pequenas, que podem coalescer ou não, raramente causam o desfolhamento das plantas. Ainda que os danos foliares possam acontecer na fase inicial da cultura eles são melhor percebidos quando a planta e a cultura estão bem estabelecidas. Ainda assim, estes danos não interferem na quantidade ou qualidade da produção, provavelmente devido ao grande número de folhas nas plantas de batata-doce e até porque é possível haver, como em outras culturas, compensação entre plantas do mesmo genótipo.

Os danos causados por insetos nas folhas são menos importantes que aqueles causados nas raízes, uma vez que estas são objetos da comercialização. Os danos nas raízes depreciam-nas comercialmente, ainda que os danos causados por crisomelídeos e elaterídeos sejam superficiais e uma vez removida a epiderme não são percebidos na polpa da batata-doce. O mesmo não acontece com a broca-da-raiz cujos danos ocorrem tanto na superfície da raiz quanto na polpa. Além de causar péssima impressão visual a quem adquire o produto, as qualidades organolépticas das raízes são alteradas de tal forma, que a produção não pode ser utilizada nem para consumo animal (Miranda et al., 1984).

Avaliação para resistência a crisomelídeos e elaterídeos em raízes tuberosas

Neste experimento, considerando-se o número de acessos e cultivares avaliados, 32, empregou-se metodologia (França et al., 1983a) que possibilita avaliação de grande número de genótipos a qual tem sido utilizada com sucesso em outros programas de melhoramento genético de batata-doce para seleção de materiais visando a resistência a crisomelídeos e elaterídeos (Silveira \& Maluf, 1994). Os genótipos definidos nesta avaliação como resistentes são consistentes com aqueles relata- 
dos por Silveira \& Maluf (1994). Os materiais mais resistentes, aos quais se atribuiu nota 1 , apresentaram em média $4,0 \pm 0,4$ furos por raíz enquanto que os suscetíveis situaram-se no extremo oposto e receberam nota $4(23,7 \pm 0,9$ furos/raiz) e nota $5(36,2 \pm 2,0$ furos/ raiz) (Tabela 2 ).

A frequência de acessos resistentes a crisomelídeos e elaterídeos no BAG de batata-doce da Embrapa Hortaliças é elevada. Isto sugere que programas de melhoramento que visem incorporar resistência a esses grupos de insetos utilizando esses acessos tem boa probabilidade de sucesso. Das raízes tuberosas, avaliadas 180 dias após o plantio das ramas (DAP), aproximadamente 50\% dos acessos do BAG foram classificados como resistentes (notas 1 e 2) e $21 \%$ receberam as mesmas notas quando a avaliação das raízes tuberosas foi feita 270 DAP (Tabela 3). Os danos nas raízes aumentam à medida que as mesmas permanecem mais tempo no solo e esta informação tem implicações tanto em programas de melhoramento genético visando resistência a insetos como para recomendações sobre manejo integrado

Tabela 2. Número de furos observados em raízes tuberosas de batata-doce às quais foram atribuídas notas de dano. Brasília, Embrapa Hortaliças, 1996.

\begin{tabular}{ccc}
\hline \multirow{2}{*}{ Nota $^{2}$} & \multicolumn{2}{c}{ Número de furos/raiz tuberosa (n = 15) $^{\mathbf{1}}$} \\
\cline { 2 - 3 } & Média \pm EPM $^{3}$ & Amplitude $^{4}$ \\
\hline 1 & $4,0 \pm 0,4$ & $(2-7)$ \\
2 & $11,1 \pm 0,9$ & $(7-16)$ \\
3 & $17,2 \pm 0,8$ & $(12-23)$ \\
4 & $23,7 \pm 0,9$ & $(19-32)$ \\
5 & $36,2 \pm 2,0$ & $(27-55)$ \\
\hline
\end{tabular}

${ }^{1} \mathrm{n}=\mathrm{n}^{\mathrm{o}}$ de raízes escolhidas ao acaso para determinação do número de furos

${ }^{2}$ Notas de dano: 1 = raiz pouco danificada; ......; 5 = raiz muito danificada

${ }^{3}$ Erro padrão da média

${ }^{4}$ Número mínimo e máximo de furos determinado para raízes escolhidas em determinada nota de dano

de pragas da batata-doce.

Assim, melhoristas devem priorizar a seleção de genótipos precoces que associem produção e qualidade agronômica em detrimento aos tardios. Porém, quanto mais tarde for feita a avaliação e a seleção de genótipos, mais confiança o avaliador poderá ter no seu procedimento uma vez que o risco de eventuais escapes serão reduzidos. Se as populações naturais de crisomelídeos e elaterídeos propiciam boas oportunidades para sele- ção de acessos resistentes pela quantidade de insetos ao longo do ano, esta condição é uma ameaça à produção comercial de batata-doce. Como consequência, quanto ao manejo de pragas da cultura, os agricultores e extensionistas devem ser orientados a colher sua produção tão logo as raízes maturem, de modo a evitar riscos na comercialização e prejuízos econômicos.

Os resultados apresentados não diferem daqueles encontrados por França

Tabela 3. Distribuições de frequências das notas de dano relativas aos furos causados por larvas de crisomelídeos e elaterídeos e da porcentagem de raízes tuberosas danificadas pela broca-da-raiz avaliados em acessos do BAG de batata-doce da Embrapa Hortaliças. Brasília, Embrapa Hortaliças, 1996.

\begin{tabular}{|c|c|c|c|}
\hline \multicolumn{4}{|c|}{ Danos nas raízes 180 D.A.P. } \\
\hline \multicolumn{2}{|c|}{ Crisomelídeos e elaterídeos } & \multicolumn{2}{|c|}{ Euscepes postfasciatus } \\
\hline Notas de dano $^{1}$ & Frequência & Classes de dano (\%) & Frequência \\
\hline 1 & 37 & $0-20$ & 266 \\
\hline 2 & 125 & $21-40$ & 35 \\
\hline 3 & 96 & $41-60$ & 21 \\
\hline 4 & 48 & $61-80$ & 2 \\
\hline 5 & 20 & $81-100$ & 6 \\
\hline Total & 326 & Total & 330 \\
\hline \multicolumn{4}{|c|}{ Danos nas raízes 270 D.A.P. } \\
\hline \multicolumn{2}{|c|}{ Crisomelídeos e elaterídeos } & \multicolumn{2}{|c|}{ Euscepes postfasciatus. } \\
\hline Notas de dano $^{1}$ & Frequência & Classes de dano (\%) & Frequência \\
\hline 1 & 4 & $0-20$ & 37 \\
\hline 2 & 13 & $21-40$ & 18 \\
\hline 3 & 21 & $41-60$ & 10 \\
\hline 4 & 29 & $61-80$ & 6 \\
\hline 5 & 13 & $81-100$ & 9 \\
\hline Total & 80 & Total & 80 \\
\hline
\end{tabular}

${ }^{1}$ Notas de dano: 1 = raiz pouco danificada; ......; 5 = raiz muito danificada 
Tabela 4. Média e erro padrão da média (EPM) da porcentagem de raízes danificadas pela broca-da-raiz e nota de dano relativa ao número de furos causados por larvas de crisomelídeos e elaterídeos avaliados em raízes tuberosas de acessos e cultivares do BAG de batata-doce da Embrapa Hortaliças. Brasília, Embrapa Hortaliças, 1997.

\begin{tabular}{|c|c|c|}
\hline \multirow[t]{2}{*}{ Acessos } & 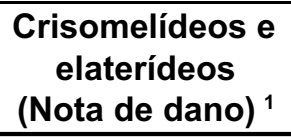 & Broca-da-raiz (\%) \\
\hline & Média \pm EPM2 & Média \pm EPM2 \\
\hline CNPH 005 & $1,0 \pm 0,0$ & $0,0 \pm 0,0$ \\
\hline CNPH 026 & $1,0 \pm 0,0$ & $0,0 \pm 0,0$ \\
\hline CNPH 295 & $1,3 \pm 0,3$ & $0,0 \pm 0,0$ \\
\hline CNPH 258 & $1,0 \pm 0,0$ & $3,3 \pm 3,3$ \\
\hline CNPH 318 & $2,0 \pm 0,6$ & $3,3 \pm 3,3$ \\
\hline CNPH 088 & $1,3 \pm 0,3$ & $4,7 \pm 4,7$ \\
\hline CNPH 314 & $1,3 \pm 0,3$ & $6,7 \pm 3,3$ \\
\hline Brazlândia Rosada & $3,3 \pm 0,7$ & $10,0 \pm 5,8$ \\
\hline CNPH 117 & $3,3 \pm 0,7$ & $10,0 \pm 5,8$ \\
\hline CNPH 200 & $3,3 \pm 0,7$ & $10,0 \pm 5,8$ \\
\hline CNPH 630 & $3,0 \pm 1,0$ & $10,0 \pm 5,8$ \\
\hline CNPH 524 & $3,3 \pm 0,3$ & $10,0 \pm 10,0$ \\
\hline CNPH 360 & $2,3 \pm 0,3$ & $13,3 \pm 8,8$ \\
\hline CNPH 403 & $2,3 \pm 0,9$ & $13,3 \pm 8,8$ \\
\hline CNPH 342 & $2,7 \pm 0,3$ & $14,0 \pm 7,0$ \\
\hline Brazlândia Roxa & $1,7 \pm 0,3$ & $16,7 \pm 3,3$ \\
\hline CNPH 076 & $4,3 \pm 0,3$ & $16,7 \pm 6,7$ \\
\hline CNPH 367 & $3,0 \pm 0,0$ & $16,7 \pm 8,8$ \\
\hline CNPH 070 & $2,0 \pm 0,0$ & $20,0 \pm 0,0$ \\
\hline CNPH 646 & $2,3 \pm 0,3$ & $20,0 \pm 10,0$ \\
\hline CNPH 690 & $2,7 \pm 0,3$ & $20,0 \pm 11,5$ \\
\hline CNPH 411 & $3,7 \pm 0,3$ & $20,0 \pm 5,8$ \\
\hline Brazlândia Branca & $2,7 \pm 0,7$ & $23,3 \pm 12,0$ \\
\hline CNPH 377 & $2,0 \pm 0,0$ & $23,3 \pm 14,5$ \\
\hline CNPH 292 & $2,0 \pm 0,0$ & $23,3 \pm 18,6$ \\
\hline CNPH 293 & $3,3 \pm 0,7$ & $23,3 \pm 3,3$ \\
\hline CNPH 402 & $3,7 \pm 0,3$ & $23,3 \pm 8,8$ \\
\hline CNPH 060 & $1,3 \pm 0,3$ & $26,7 \pm 3,3$ \\
\hline CNPH 046 & $4,3 \pm 0,7$ & $33,3 \pm 8,8$ \\
\hline CNPH 480 & $3,0 \pm 1,2$ & $44,0 \pm 22,6$ \\
\hline CNPH 676 & $2,7 \pm 0,3$ & $52,5 \pm 24,3$ \\
\hline Princesa & $3,3 \pm 0,3$ & $53,3 \pm 13,3$ \\
\hline DMS (5 \%) & 1,4 & 27,6 \\
\hline
\end{tabular}

${ }^{1}$ Notas de dano: 1 = raiz pouco danificada; ......; 5 = raiz muito danificada

${ }^{2}$ Erro padrão da média.

et al. (1983a) e reforçam a conclusão alcançada por Silveira \& Maluf(1994), confirmada por Peixoto et al. (1999), de que o método de avaliação através de escala de notas é eficiente na medida que permite a seleção de genótipos suscetíveis e resistentes com confiança, rapidez e segurança. A cultivar de batatadoce Brazlândia Roxa, recomendada pela Embrapa Hortaliças como resisten- te a crisomelídeos (Miranda et al., 1984), obteve nota mais baixa (nota 1,7 ) que as cultivares comerciais Brazlândia Branca (nota 2,7) e Princesa (nota 3,3) (Tabela 4), as quais podem ser classificadas como moderadamente suscetíveis. A mesma classificação foi atribuída à Brazlândia Branca por Silveira \& Maluf (1994). Estes resultados também são semelhantes àqueles obtidos por Peixoto et al. (1999). Foram identificados ainda sete genótipos com nota inferior à alcançada por Brazlândia Roxa. Alguns destes acessos (CNPH 005, CNPH 026 e CNPH 258), foram homogêneos e consistentes nas três avaliações obtendo a nota 1,0. Os mesmos são promissores e podem ser explorados no futuro, ainda que os ganhos em resistência não venham a ser tão elevados (Tabela 3). Informações sobre acessos mantidos no BAG/batata-doce da Embrapa Hortaliças foram apresentadas por Ritschel et al. (1999).

Avaliação para resistência à broca-da-raiz

Foi identificada variabilidade genética para resistência à broca-da-raiz entre os acessos avaliados, mas esta metodologia deve ser refinada de modo a melhor separar os genótipos resistentes dos suscetíveis. Os intervalos de classes de danos, que na avaliação inicial foi estimado em $20 \%$, são úteis quando grande quantidade de clones precisa ser selecionada (Tabela 3). Contudo, há necessidade de considerarem-se novos intervalos, por exemplo, $5 \%$ ou $10 \%$ (Tabela 4), para melhor resolução dos resultados nas fases mais avançadas de programas de melhoramento genético visando resistência à broca-da-raiz. Costa (1961), não trabalhou com percentagem de raízes danificadas, mas utilizou uma escala de notas de 0 (nenhum dano/ nenhuma larva e/ou pupa) a 5 (muito dano; presença de larvas e/ou pupas), para avaliar o impacto de inseticidas no controle da broca-da-raiz. Esta metodologia precisa ser melhor definida em estudos de resistência a insetos, considerando os resultados obtidos por Garcia (1989) que utilizou critério de notas 0 a 5 apropriando estas, à variação percentual de dano (0-100\%), que se aproxima parcialmente do critério de avaliação utilizado nos experimentos cujos resultados são descritos neste trabalho. 
Avaliando 44 clones e cultivares de batata-doce do Banco de Germplasma do IPA e da UFRPE, Garcia (1989) em critério denominado "estabilidade da resistência em relação ao ecossistema" (desempenho dos genótipos nos três ecossistemas testados), não classificou nenhuma das cultivares testadas como resistente. $\mathrm{O}$ autor destacou apenas duas cultivares como "menos suscetíveis": Rama Curta Roxa e Caboatã. As demais, entre as quais se incluíam as cultivares Centenial e Dahomey, foram todas consideradas altamente suscetíveis. Nos experimentos conduzidos na Embrapa Hortaliças, os clones CNPH 005, CNPH 026, CNPH 295, CNPH 258, CNPH 318, CNPH 088 e CNPH 314 tiveram $7 \%$ ou menos das raízes danificadas por E. postfasciatus enquanto as cultivares Brazlândia Branca, com 23,3\% e Princesa, com 53,3\%, além de nove acessos estiveram entre os mais suscetíveis (Tabela 4). Informações sobre a origem e caraterísticas desses acessos são apresentadas por Ritschel et al. (1999).

Infestações naturais da broca-da-raiz também são problemáticas nas avaliações em grande escala e isto provavelmente se deve às características da relação da espécie que é onívora e cujo ciclo pré-imaginal é longo (Raman \& Alleyne, 1991). Garcia (1989) valeu-se de infestações naturais da broca-da-raiz, que no Estado de Pernambuco é endêmica, mostrando ser mais prudente, como garantia, instalar os ensaios de campo em áreas onde previamente batata-doce foi cultivada com a presença do inseto a se tentar infestações em laboratório ou trazidas de outro campo de produção. A não ser que se infeste a área com muitos insetos, não haverá tempo suficiente para que populações introduzidas colonizem a área causando os danos que possibilitem a separação dos clones resistentes dos suscetíveis. No caso dos crisomelídeos e elaterídeos, seleções tardias dos clones aos 270 DAP são mais proveitosas e consistentes que aquelas realizadas até 180 DAP (Tabela $3)$. Contudo, deve se alertar para o risco de que neste processo poderão ser descartados clones com resistência moderada, os quais poderiam ser úteis se utilizados junto com outras táticas de controle (Brett et al., 1961; Cuthbert \& Jones 1978; Jones et al., 1981).
A prolongação do ciclo vegetativo da batata-doce ou a colheita tardia das raízes é uma prática muito comum adotada por agricultores como estratégia para reduzir oferta de produto ao mercado e manter bons preços para sua produção. Não se conhece nenhum estudo onde tenha sido comprovada a eficácia desta estratégia, até porque são poucos os produtores que mantêm registro das partes da produção descartadas por danos causados por insetos. Os resultados obtidos através desses experimentos sugerem que os danos causados por insetos de solo, sejam eles crisomelídeos, elaterídos ou a broca-da-raiz aumentam de uma forma tal, que em 90 dias, reduziu em $50 \%$ o número de acessos resistentes e aumentou de oito a dez vezes em termos percentuais a frequência de acessos suscetíveis.

Se o comportamento e biologia da broca-da-raíz trazem dificuldades para os melhoristas, estas características da espécie podem e devem ser utilizadas para melhorar a eficiência de controle nas áreas de produção comercial. Assim, a rotação de culturas evitando-se o plantio sucessivo, além do plantio de genótipos precoces, colheita de toda a área cultivada na época apropriada e a remoção e destruição de restos culturais são práticas culturais eficientes para se obter produções livres do inseto.

Não foi observada correlação entre danos causados por crisomelídeos e elaterídeos e aqueles causados pela broca-da-raiz. Aparentemente, os fatores condicionando a resistência a $E$. postfasciatus são diferentes daqueles que definem a resistência a Diabrotica spp e Conoderus spp.

\section{AGRADECIMENTOS}

Os autores agradecem ao Conselho Nacional do Desenvolvimento Científico e Tecnológico (Processo n ${ }^{\circ}$ 520304/ 97.7) pela bolsa individual de pesquisa concedida. A Ornélio Guedes da Silva, Hozanan Pires Chaves, José Gomes Teixeira e Ronildo Costa Gonçalves pelo apoio técnico na condução deste trabalho. À Maria Fátima Bezerra Ferreira Lima e Paulo Fraga Jr. pelo apoio bibliográfico e à Marina Castelo Branco e Maria Alice de Medeiros e a dois anônimos revisores da Horticultura Brasileira pelas boas sugestões, que foram incorporadas a este manuscrito.

\section{LITERATURA CITADA}

BARLOW, T.; ROLSTON, L.H. Types of host plant resistance to the sweet potato weevil found in sweet potato roots. Journal Kansas Entomological Society, v. 54, p. 649-657, 1981.

BONDAR, G. Insetos daninhos e moléstias da batata-doce no Brasil. O Campo, Rio de Janeiro, v. 1, n. 11, p. 33-36, 1930.

BONDAR, G. Batata-doce: a sua cultura, variedades conhecidas na Bahia e inimigos. Salvador: Boletim da Secretaria de Agricultura da Bahia, 1931. 44 p.

BRAGA, E.C. Resistência de cultivares de batata-doce (Ipomoea batatas (L.) Lam.) à broca-deraiz, Euscepes postfasciatus (Fairmaire, 1849) (Coleoptera, Curculionidae) em Pernambuco. 1993. 59 p. (Dissertação mestrado), UFRP, 1993. BRETT, C.H.; McCOMBS, C.L.; DAUGHERTY, D.M. Resistance of squash varieties to the pickleworm and the value of resistance to insecticidal control. Journal of Economic Entomology, v. 54, p. 1191-1197, 1961.

COSTA, J.M. Controle das brocas da batata-doce Euscepes postfasciatus; (Fairmaire, 1849) (E. batatae; Waterhouse, 1859) Coleoptera Curculionidae e Megastes pusialis; Snellen, 1875, Lepidoptera - Pyraustidae. Cruz das Almas: IPEAL, 1961. 42 p. (IPEAL. Boletim Tecnico, 1). CUTHBERT Jr., F.P.; JONES, A. Insect resistance as na adjunct or alternative to insecticides for control of sweet potato soil insects. Journal of the American Society for Horticultural Sciences, v. 103, p. 443-445, 1978.

CUTHBERT Jr., F.P.; DAVIS Jr., B.W. Factors associated with insect resistance in sweet potatoes. Journal of Economic Entomology, v. 64, p. 713717, 1971.

FRANÇA, F.H.; MIRANDA, J.E.C.; ROSSI, P.E.F.; MALUF, W.R. Comparação de dois métodos de avaliação de germoplasma de batata-doce visando resistência a pragas de solo. In: $\mathrm{CON}-$ GRESSO BRASILEIRO DE OLERICULTURA, 23, Rio de Janeiro, 1983a. Resumos... Rio de Janeiro, SOB, 1983. p. 176 a.

FRANÇA, F.H.; MIRANDA, J.E.C.; ROSSI, P.E.F., MALUF, W.R.; BARBOSA, S. Avaliação de germoplasma de batata-doce Ipomoea batatas (L.) Lam. visando resistência a insetos de solo. In: CONGRESSO BRASILEIRO DE OLERICULTURA, 23, Rio de Janeiro, 1983b. Resumos... Rio de Janeiro, SOB, 1983. p. 177.b. FRANÇA, F.H. A batata-doce no Brasil: Produção, pesquisa e difusão de tecnologia. In: MEJORAMIENTO DE LA BATATA (Ipomoea batatas) EN LATINOAMÉRICA. Lima, 1987. Memorias. Lima, Centro Internacional de la Papa. 1989. p. 39-56.

GARCIA, M.S. Aspectos biológicos da broca da raiz Euscepes postfasciatus (Fairmaire, 1849) (Coleoptera, Curculionidae) e resistência de cultivares de batata-doce (Ipomoea batatas (L.)Lam.), no Estado de Pernambuco. 1989. 148 p. (Dissertação mestrado), UFRP, 1989. 
JONES, A.; DUKES, P.D.; CUTHBERT Jr., F.P. W-13 and W-178 sweet-potato germplasm. HortScience, v. 10, p. 533, 1975.

JONES, A.; SCHALK, J.M.; DUKES, P.D. Progress in selection for resistances in sweet potato to soil insects of the WDS complex. International Symposium on Sweet Potato, 1., 1981. Proceedings... Taiwan, China, AVRDC, 1981. p. 337-344.

JONES, A.; DUKES, P.D.; SCHALK, J.M.; HAMILTON, M.G.; MULLEN, M.A.; BAUMGARDNER, R.A.; PATERSON, D.R.; BOSWELL, T.E. 'Resisto' sweet potato. HortScience, v. 18, p. 251-252, 1983.

MALUF, W.R.; FRANÇA, F.H.; MOURA, W.M. CASTELO BRANCO, M.; MIRANDA, J.E.C. Screening of sweet potato accessions for resistance to Tetranychus spp. mites. Revista Brasileira de Genética, Ribeirão Preto, v. 10, n. 3, p. 603-610, 1987.

MARTINEZ, C.D. Comportamento e mecanismo de resistência de cultivares de batata-doce (Ipomoea batatas (L.) Lam.) à broca do caule, Megastes grandalis (Guenée, 1854) (Lepidoptera, Pyralidae). 1985. 109 p. (Dissertação mestrado), UFRP, 1985.
MIRANDA, J.E.C.; FRANÇA, F.H.; CARRIJO, O.A.; SOUZA, A.F.; AGUILAR, J.A.E. Cultivo da batata-doce (Ipomoea batatas (L.) Lam.). Brasília, EMBRAPA-CNPH, 1984. 8 p.

MIRANDA, J.E.C.; FRANÇA, F.H. Melhoramento de batata-doce no CNP Hortaliças. In: Anais do Seminário sobre a cultura da batata-doce. EMBRAPA-Centro Nacional de Pesquisa de Hortaliças. p. 65-74, 1988.

MULLEN, M.A.; JONES, A.; DAVIS, R.; PEARMAN, G.C. Rapid selection of sweet potato lines resistant to the sweet potato weevil. HortScience, v. 15, p. 70-71, 1980.

NOVO, R.J. Alternativas de controle de Megastes spp. (Lepidoptera, Pyralidae) e Euscepes postfasciatus Fairm., 1849 (Coleptera, Curculionidae), em batata-doce (Ipomoea batatas(L.) Lam.) no Estado de Pernambuco. 1983. 113 p. (Dissertação mestrado), UFRP, 1983. PEIXOTO, J.R.; SANTOS, L.C.; RODRIGUES, F.A.; JULIATTI, F.C.; LYRA, J.R.M. Seleção de clones de batata-doce resistentes a insetos de solo. Pesquisa Agropecuária Brasileira, Brasília, v. 34, n. 3, p. 385-389,1999.
RAMAN. K.V.; ALLEYNE, E.H. Biology and management of the west indian sweet potato weevil, Euscepes postfasciatus. In: Jansson, R.K \& Raman, K.V. (Eds): Sweet potato pest management: A global perspective. Bouder, Westview Press. 1991. p. 263-282.

RITSCHEL, P.S.; HUAMAN, Z.; LOPES, C.A.; MENEZES, J.E.; TORRES, A.C. Catálogo de germoplasma de batata-doce. I. Coleção mantida pela Embrapa Hortaliças. Brasília: Embrapa Hortaliças, 1999. 47 p. (Embrapa Hortaliças, Documentos, 23).

ROLSTON, L.H.; BARLOW, T.; HERNANDEZ, T.; NILAKHE, S.S. Field evaluation of breeding lines and cultivars of sweet potato for resistance to the sweet potato weevil. HortScience, v. 14, p. 634-635, 1979.

SILVEIRA, M.A.; MALUF, W.R. Avaliação de clones de batata-doce quanto a resistência de solos. Horticultura Brasileira, Brasília, v. 12, n. 1, p. 40-42, 1994 